\title{
Chronic administration of a positive allosteric modulator at the $\alpha 5$-GABAA receptor reverses age-related dendritic shrinkage
}

Thomas D. Prevot ${ }^{1 *}$, Akiko Sumitomo ${ }^{1}$, Toshifumi Tomoda ${ }^{1}$, Daniel E. Knutson ${ }^{2}$, Guanguan Li ${ }^{2}$, James M. Cook $^{2}$ and Etienne Sibille ${ }^{1,3,4}$.

${ }^{1}$ Campbell Family Mental Health Research Institute of CAMH, Toronto, Canada

${ }^{2}$ Department of Chemistry and Biochemistry, University of Wisconsin-Milwaukee, Milwaukee, USA

${ }^{3}$ Department of Psychiatry, University of Toronto, Toronto, Canada

${ }^{4}$ Department of Pharmacology and Toxicology, University of Toronto, Toronto, Canada

*Corresponding Author

Thomas D. Prevot, Ph.D., CAMH, 250 College street, room 131, Toronto, ON M5T 1R8, Canada

Tel: 416-535-8501, ext 33785; E-mail: thomas.prevot@camh.ca

Key Words: Aging / Cognition / GABA / Positive Allosteric Modulator / Neurotrophic / Spine / Dendrite 


\section{ABSTRACT}

Over the last 15 years, worldwide life expectancy increased by 5 years jumping from 66 years to 71 years. With progress in science, medicine, and care we tend to live longer. Such extended life expectancy is still associated with age-related changes, including in the brain. The aging brain goes through various changes that can be called morphomolecular senescence. Overall, the brain volume changes, neuronal activity is modified and plasticity of the cells diminishes, sometimes leading to neuronal atrophy and death. Altogether, these changes contribute to the emergence of cognitive decline that still does not have an efficient treatment available. Many studies in the context of cognitive decline focused on pathological aging, targeting $\beta$-amyloid in Alzheimer's disease, for example. However, $\beta$-amyloid plaques are also present in healthy adults and treatments targeting plaques have failed to improve cognitive functions. In order to improve the quality of life of aging population, it is crucial to focus on the development of novel therapies targeting different systems altered during aging, such as the GABAergic system. In previous studies, it has been shown that positive allosteric modulators (PAM) acting at the $\alpha 5$-containing GABA-A receptors improve cognitive performances, and that these $\alpha 5-G A B A-A$ receptors are implicated in dendritic growth of pyramidal neurons. Here, we hypothesized that targeting the $\alpha 5-G A B A-A$ receptors could contribute to the reduction of cognitive decline, directly through activity of the receptors, and indirectly by increasing neuronal morphology. Using primary neuronal culture and chronic treatment in mice, we demonstrated that an $\alpha 5-P A M$ increased dendritic length, spine count and spine density in brain regions involved in cognitive processes (prefrontal cortex and hippocampus). We also confirmed the procognitive efficacy of the $\alpha 5$-PAM and showed that the washout period diminishes the precognitive effects without altering the effect on neuronal morphology. Future studies will be needed to investigate what downstream mechanisms responsible for the neurotrophic effect of the $\alpha 5$-PAM. 


\section{Introduction}

Thinking about cognitive decline in aging, the first things that come in mind are Alzheimer's disease and related dementias, but human and animal suffer from cognitive decline during normal aging without necessarily developing neurodegenerative diseases. With progress in medicine and health care, human population tends to live longer. Since 2018, persons aged 65 or above have outnumbered children under 5 years of age globally $(1,2)$. By 2050 , it is estimated that $16 \%$ of the global population will be over 65 years of age, while in 2019 only $9 \%$ of the population is over 65 years of age $(2,3)$. Overall, such extended lifespan is accompanied by normal cognitive decline and brain changes.

Normal aging has been studied for decades and it is now acknowledged that neurocognitive, structural, functional and cellular changes are hallmarks of aging (4). Cognitive changes with aging are not necessarily associated with poorer functions. For example, vocabulary use or general knowledge and expert skills remain intact or can even improve with aging $(5,6)$. In the other hand, other functions such as problem solving (7), memory (8,9), processing speed (10) and psychomotor abilities (11) (also known as executive functions) suffer gradual impairment with increasing age. More specifically, episodic memory (12) (memory of personal experienced events) and working memory (13) (temporary maintenance, storage and update of information while performing a task) are altered during aging (8).

Cognitive decline was linked with brain changes at multiple levels that can be defined as "morphomolecuclar senescence"(14). Aging causes a grey matter volume decline, particularly in the frontal areas of the cortex (anterior cingulate cortex: (15)). Subcortical regions including the hippocampus, brain region critically involved in cognitive processes, also suffer from volume atrophy (16). Such decrease in grey matter in frontal areas and in the hippocampus has been suggested to be caused by neuronal shrinkage and death $(17,18)$, altogether contributing to cognitive decline. Pyramidal neurons, excitatory neurons in cortical layers, are particularly vulnerable during aging (19-21), and exhibit reduced spine density and dendritic shrinkage during normal aging. This neuronal atrophy has been showed across species, from human post mortem studies (22) to rodents (23), including monkeys (24). Multiple factors contribute to neuronal shrinkage during normal aging, including, neuroinflammation (25) accumulation of $\beta$-amyloid (26-29) or dysregulation of neuronal excitation-inhibition (21).

Neuroinflammation and $\beta$-amyloid load have been extensively studied, especially in the context of Alzheimer's disease (30-32). However, more and more studies are showing that amyloid load is a normal process during aging (29), and the relationship between amyloid load and cognitive decline remains 
uncertain in healthy elderly $(33,34)$. Multiple pharmaceutical companies tried to develop treatment by targeting $\beta$-amyloid plaques(35), with very limited success to date (36). To increase the changes of success at countering cognitive decline, scientists have to explore other paths than $\beta$-amyloid.

Neuronal activity and the excitation/inhibition balance is also impaired during normal and pathological aging. Some studies have shown conflicting results sometimes suggesting a decreased excitability of neurons toward a hyper-inhibition $(37,38)$, and sometimes showing overall decrease in both excitation and inhibition (39-41). GABAergic neurons represents the major inhibitory players to control excitability of excitatory cells. Using magnetic resonance spectroscopy, GABAergic activity has been shown to be downregulated during normal and pathological aging, and such deficit in GABA was associated with cognitive decline (42). GABA signal through two main types of receptor, known as GABA$A$ and GABA-B receptors. The GABA-A receptors are ion-channel receptors that hyperpolarize the postsynaptic cell by chloride influx (43). The GABA-A receptors are pentameric, composed of a combination of 5 subunits between $\alpha, \beta, \gamma, \delta, \varepsilon, \theta, \pi$ and $\rho(44)$. The different subunits of the GABA-A receptors show variable dysregulation with aging, depending on the brain regions (45). Some studies showed downregulation of $\alpha_{1}, \beta_{1}, \beta_{2}, \gamma_{1}$ and $\gamma_{2}$ subunits in the rat auditory cortex (46) and others showed that $\alpha_{3}$ and $\alpha_{5}$ subunits were downregulated in the rat motor cortex (47). Other studies also showed an upregulation of the $\alpha_{1}$-subunit in the hippocampus of old rats (48), while a decrease of the same subunit was observed in monkeys (49). Despite variability in the changes of the GABA-A receptors associated with age, all studies agree that decrease in the number of GABA-A receptors can result in behavioral changes (50), including cognitive deficits (51). The $\alpha_{5}$-subunit has a particular distribution in the brain, as it is located exclusively in brain regions highly involved in cognitive processes, such as the hippocampus and the prefrontal cortex (52). Preclinical and clinical data showed that the $\alpha_{5}$-subunit is downregulated in aging (53-55), and a recent study showed that synaptic localization of $\alpha_{5}$-containing GABA-A receptors contributes to dendritic outgrowth and spine maturation (56). Altogether, this data suggests a critical role of this particular subunit in the regulation of cognitive function mediated by the GABAergic system, directly through reversal of decreased activity of the receptor during aging, or indirectly through dendritic growth.

Benzodiazepine, such as diazepam, bind at the interface between the $\alpha_{1,2,3,5}$-subunit and the $\gamma$-subunit (57), act as a positive allosteric modulator (PAM) and are the most commonly prescribed medication for the treatment of anxiety, widely prescribed to elderly despite apparent issues and complications linked with age (58). The wide range of activity at different subunits is responsible for considerable side effects 
that can be potentiated by the GABAergic dysregulation occurring during normal or pathological aging (48). Novel developments have tried to reduce the side effects of novel benzodiazepines, or derivatives, by increasing selectivity to the $\alpha_{5}$-subunit and reducing selectivity to the $\alpha_{1}$-subunit (59). Previous data from our group showed that the $\alpha_{5}$ - positive allosteric modulator ( $\alpha_{5}$-PAM) GL-II-73 improves working memory in mouse model of chronic stress and aging (59). Other group demonstrated improved cognitive functions in old rats using different $\alpha_{5}$-PAMs, namely Compound 44 and Compound 6 (60). Knowing the distribution of the $\alpha_{5}$-subunit in the brain, its downregulation during aging, its potential role in dendritic growth, and the known procognitive effect of GL-II-73 in old mice, we hypothesized that facilitating the action of GABA at the $\alpha_{5}$-GABA receptors with GL-II-73 will improve cognitive functions in old mice, directly through activity at the receptor, and indirectly through reversal of dendritic shrinkage due to normal aging. To validate our hypothesis, we used primary neuronal culture from mouse hippocampus to test the effect of GL-II-73 in vitro, at promoting dendritic growth. We then tested the effect of GL-II-73 in vivo, in old mice, to demonstrate if chronic treatment can improve cognitive deficits and reverse dendritic shrinkage, and if such effects are maintained when the treatment stops. 


\section{Material and Methods}

\section{Animals}

For the cell culture experiment, heterozygote CamKII-Cre male mice (Jackson Laboratories, Cat\#5359) were crossed with Rosa26-flox-stop-GFP female mice to express the green fluorescent protein (GFP) exclusively in pyramidal neuronal. The pregnancy of the females was timed, in order to collect embryos at E14 for primary cortical neuronal culture. Pups were quickly decapitated, and the prefrontal cortex was harvested for primary neuronal culture. For the behavioral experiment, two separate cohorts of 30 male C57BL6 mice were purchased as retired breeders from Charles River Laboratories at the age of 9-10 months, and kept in the animal facility until they reach the age of 22 months. Two cohorts of young male C57BL6 mice (N1=11; N2=8) were purchased separately to include a group of young mice for each cohort of old mice. Seven retired breeders from the first cohort, and 12 from the second cohort died of normal aging before the initiation of the behavioral tests.

\section{Primary cortical neurons in culture and morphometric analysis}

To visualize dendritic and spine morphology of major output neurons in culture, we prepared primary cortical neurons (61) and maintained the culture for up to 25 days by replacing half the media (Neurobasal media supplemented with B-27 [GibcoBRL]) every other day. To evaluate dendritic branching complexity, ImageJ with Sholl analysis plug-in (http://fiji.sc/Sholl_Analysis) is used to score the number of intersections of dendritic arbors with a series of concentric spherical shells drawn from the soma with periodic distance. Numbers of spines along all apical dendritic branches (except for the main shaft of apical dendrite) per cell are scored by ImageJ with bio-formats plug-in, and the average spine numbers per 100 $\mu \mathrm{m}$ length are calculated.

\section{Drug preparation}

The positive allosteric modulator (PAM) at the $\alpha_{5}$-containing GABA-A receptor $\left(\alpha_{5}\right.$-PAM) GL-II-73 was synthesized in collaboration with Dr. Cook's group (University of Wisconsin-Milwaukee). For the neuronal culture, the $\alpha 5$-PAM GL-II-73 was infused in the media at the concentration of $1 \mu \mathrm{M}$, in $0.01 \% \mathrm{DMSO}$. The vehicle solution was only $0.01 \%$ DMSO, mixed in the media. The drug was left incubating in the culture for $24 \mathrm{hrs}$. For the behavioral studies, GL-II-73 was administered through the drinking water at a dose of $30 \mathrm{mg} / \mathrm{kg} /$ day, for 30 days, based on previous studies from our group (59).

Open Field 
Mice were habituated to the room lit at 75lux for 30 minutes prior to testing. The apparatus was a grey PVC arena $(43 \times 43 \mathrm{~cm})$ with walls $43 \mathrm{~cm}$ high. A digital camera was mounted to record the animals' activity in the arena for 10 minutes. Post-acquisition videos were analyzed using the software ANYmaze (Stoelting). Distance travelled in meters $(\mathrm{m})$ was measure as a proxy for locomotor activity.

\section{Y-Maze Alternation Task}

The apparatus is made of black PVC, shaped like a Y, with a sliding door at the entry of each arm. Mice were habituated to the maze, by letting them explore the maze freely for 10 minutes per day, for 2 days. On the third day, mice were trained to alternate in the maze. Each animal was placed in the starting box for 30 seconds, before opening of the door. Once the door was opened, the animal could decide to visit the right or left arm of the maze. Once chosen, the animal was confined into that arm for 30 seconds. Then, the animal was gently transferred back to the starting box, with 30 seconds inter-trial-interval (ITI), prior to the next trial, identical to the previous one. If the animal did not alternate over 3 consecutive trials, the animal was then forced to alternate in order to prevent any reinforcement of one arm. This sequence was followed for 7 trials. Finally, on the fourth day, animals are subjected to the same sequence of testing but with a $60 \mathrm{sec}$ ITI. Also, an $8^{\text {th }}$ trial with a $5 \mathrm{sec}$ ITI is implemented to assess potential loss of motivation. In the event of a lack of alternation at the $8^{\text {th }}$ trial, mice were removed from the statistical analysis.

\section{Brain collection and staining}

Twenty-four (24) hours after completion of the last behavioral test, mice were euthanized using cervical dislocation, and their brains were harvested for downstream analysis. Four brains per group were used for the Golgi-Cox staining. The remaining brains were kept as backups, or for follow-up analyses. The brain extraction and initial immersion of Golgi staining procedure were conducted in $\mathrm{CAMH}$, with Golgi-Cox staining solutions provided by NeuroDigiTech LLC. The brain samples were then shipped to NeuroDigiTech for sectioning and blinded morphological analysis in layers II/III of the prefontal cortex (PFC) and CA1 region of the hippocampus (CA1).

\section{Selection of the regions of interest and samplings}

Brains were sectioned on a cryostat, and slices were mounted on glass slides. The slides included serial coronal sections that covered the anterior-to-posterior axis of the brain. The sampling of the regions of interest (ROIs) included the basal and apical dendrites of pyramidal cells in Layers II/III of PFC and the CA1 of the hippocampus. The ROIs were then chosen and analyzed using the stereology-based software NeuroLucida v10 (Microbrightfield, VT), installed on a Dell PC workstation that controlled Zeiss Axioplan 
2 image microscope with Optronics MicroFire CCD camera (1600 x 1200) digital camera, motorized X, Y, and Z-focus for high-resolution image acquisition and digital quantitation. The sampling process was conducted as follows: the investigators first previewed the entire rostro-caudal axis of ROls, under lowmag Zeiss objectives (10x and 20x), compared and located those with the least truncations of distal dendrites as possible under high-mag Zeiss objectives (40x and 63x), and then used a Zeiss 100x objective with immersion oil to perform 3D dendritic reconstruction, followed by counting of the spines throughout the entire dendritic trees. The criteria for selecting candidate neurons for analysis ( $n=6$ per animal) were based on visualization of a completely filled soma with no overlap of neighboring soma and completely filled dendrites, the tapering of most distal dendrites; the visualization of the complete 3-D profile of dendritic trees using the 3-D display of imaging software. Neurons with incomplete impregnation and/or neurons with truncations due to the plane of sectioning were not collected. Moreover, cells with dendrites labeled retrogradely by impregnation in the surrounding neuropil were excluded (derived from (62)).

For spine sampling, only spines orthogonal to the dendritic shaft were readily resolved and included in this analysis, whereas spines protruding above or beneath the dendritic shaft were not sampled. This principle was remained consistent throughout the course of analysis. After completion, the digital profile of neuron morphology was extrapolated and transported to a multi-panel computer workstation for the quantitative analysis, including the dendrograms, spine counts, and Sholl analyses.

\section{Experimental Design}

In the first experiment, 11 young and 22 old mice were included. Among the 22 old mice, 8 received GLII-73 in the drinking at the dose of $30 \mathrm{mg} / \mathrm{kg}$, while the other 14 received only water. This group design is due to the limited availability of the drug that did not allow more animals to be included in the treatment group. Similarly, in the second study, 8 young and 18 old mice were included. Among the old mice, 6 received water, 6 received GL-II-73 and 6 received GL-II-73 with a 1-week washout. All young mice from both behavioral experiments received water for the entire duration of the study. In each group, 4 mice were used to the Golgi staining analyses. Selection of the animals for this study was random, and ensured to be representative of the average performances of the group at large.

\section{Statistical analysis}

In the cell culture experiment, the average number of intersection depending on the distance from the soma, and the treatment group was analyzed using 2-way ANOVA in repeated measure. Statistical differences were then characterized using Scheffe's test. The average spine count per group was analyzed using a $t$-test (two-tailed). Behavioral performances were analyzed using 1-way ANOVA followed by post 
hoc analyses when significance was reached (Scheffe's test). To quantify the dendritic length, spine count and spine density the samples, 6 cells per animal per brain region were used. The total of each feature was quantified, as well as the detail of each feature on the apical or basal segment of the dendrite. Repeated measure ANOVA taking into consideration each cell quantified for its dendritic length, spine count and spine density was performed with "group" as the independent variable. If a significant difference was found, Tukey's multiple comparison test was performed to identify the differences between groups. Correlation analyses were also performed between quantification in the PFC and the CA1 using linear regression. 


\section{Results}

\section{Infusion of GL-II-73 in neuronal culture increases dendritic complexity}

The $\alpha 5$-PAM GL-II-73 was infused in neuronal culture expressing GFP, and imaged after 24hr (Fig.1A). The number of intersection between dendrites and concentric circles $10 \mu \mathrm{m}$ apart from each other (Scholl analysis) were analyzed (Fig.1B). Repeated measure ANOVA on 10 neurons per group showed a significant effect of GL-II-73 $(p<0.05)$. Post hoc analysis identified an increase in intersection in the neurons treated with GL-II-73 between 30 and $50 \mu \mathrm{m}$ from the cell body. Analysis of the spine number also showed a significant increase in neurons treated with GL-II-73 compared to neurons treated with vehicle $(p<0.001$; Fig.1C).

\section{Chronic treatment with GL-II-73 increases spatial working memory performances in old mice}

After confirmation of the potential effect of GL-II-73 on dendritic morphology in vitro, we investigated the effect in vivo. Old mice received chronic administration of GL-II-73 in the drinking water for 4 weeks before being tested in the open-field to assess locomotor activity, and in the Y-Maze to assess spatial working memory (Fig.2A). ANCOVA performed on the distance travelled in the open field (Fig2.B) showed no significance differences between group $\left(F_{(2 ; 31)}=2.4 ; p>0.1\right)$. ANCOVA performed on the percentage of alternation (Fig.2C) showed significant differences between groups $\left(F_{(2 ; 25)}=11.34 ; p<0.001\right)$. Posthoc analysis identified a significant decrease of alternation with age ("Old" versus "Young"; $p<0.001$ ) that is reversed by chronic treatment of GL-II-73 ("old+GL-II-73" versus “old", p<0.05). The "old+GL-II-73" group was not significantly different from the "young" group ( $p>0.1)$.

\section{Chronic treatment with GL-II-73 reverses cellular morphology changes related to aging}

From each group, four mice were euthanized and brain were collected for Golgi staining. After staining, brains were shipped to NeuroDigiTech for sectioning and blinded quantification of dendritic length, spine count and spine density in the PFC and CA1 of the dorsal hippocampus. Imaging of pyramidal neurons from the PFC are presented for each group in Fig.3A., with a close-up visualization of the spines at the apical segment of the pyramidal neuron. Overall dendritic length was significantly different between group (ANOVA $F_{(2 ; 143)}=5.5 p<0.05$; supplementary figure 1A). Post hoc analyses showed that "old" mice had shorter dendritic length compared to "young" mice, while "old+GL-II-73" mice were neither significantly different from the "old" group nor the "young" group ( $p>0.05)$. When analyzed per dendritic segment (apical versus basal), data showed no difference between groups in the basal segment (ANOVA $F_{(2 ; 71)}=1.07 p>0.05 ;$ Fig3.B), while a group difference was observed in the apical segment (ANOVA $F_{(2 ; 71)}=5.3$ 
$p<0.05$; Fig3.C). Posthoc analyses identified a significant decrease in dendritic length due to normal aging ("old" versus "young": p<0.01) that was reversed by chronic treatment with GL-II-73 ("old+GL-II-73" versus "old"; $p<0.05)$.

Similarly, repeated measure ANOVA performed on the total spine count showed a significant difference between groups $\left(F_{(2 ; 143)}=16.29 p<0.001\right.$; supplementary figure 1B), explained by significant decrease of spine count with age ("young" versus "old": p<0.001), reversed by chronic treatment with GL-II-73 ("old+GL-II-73" versus "old": p<0.05). However, mice receiving the drug still had less spines than young mice $(p<0.05)$. When looking closely at the dendritic segments, repeated measures ANOVA on the spine counts from the basal segment showed significant differences $\left(F_{(2 ; 71)}=6.09 p<0.001\right.$, Fig3.D). Posthoc analyzes identified a significant decrease with age ("old" versus "young": $p<0.01$ ) but no further significant differences. In the apical segment (Fig.3E), spine count was also significantly different between groups (repeated measure ANOVA, $\left.F_{(2 ; 71)}=10.54 ; p<0.001\right)$, explained by significant decrease with age ("old" versus "young": $p<0.001$ ), reversed by chronic treatment ("old+GL-II-73" versus "old": $p<0.05$ ). No statistical differences were observed between "young" and "old+GL-II-73" ( $p>0.05$ ).

Spine density was also measured. Repeated measure ANOVA on the total spine density (supplementary figure 1C) showed significant differences between groups $\left(F_{(2,143)}=17.93 ; p<0.001\right)$, explained by decrease spine density with age ("old" versus " young": p<0.001), reversed by chronic treatment with GL-II-73 ("old+GL-II-73" versus "old": p<0.01). A significant difference was observed between "old+GL-II-73" and "young" ( $p<0.05)$. When focusing on the basal segment (Fig.3F), a significant difference was identified (repeated measure ANOVA, $F_{(2 ; 71)}=9.24, p<0.001$ ) and is characterized by decreased spine density with age ("old" versus "young": p<0.001). In the apical segment (Fig.3G), repeated measure ANOVA showed significant group differences $\left(F_{(2 ; 11)}=10.1 ; p<0.001\right)$, characterized by reduced spine density due to aging, regardless of the drug treatment ("old" versus "young", and "old+GL-II-73" versus "young": ps<0.05).

The same analyses were carried out in the CA1 region of the dorsal hippocampus (supplementary Figure 2). Conversely, total dendritic length, total spine counts and spine density (supplementary figure 3A-C) were significantly decreased by age (repeated measure ANOVAs $F_{(2 ; 143)}>9.1 ; p s<0.05-$ posthoc $p s<0.05$ ), and reversed by chronic treatment with GL-II-73 (ps<0.05). Looking at dendritic length, spine counts and spine density in the basal segment (supplementary figure 3D-F), repeated measure ANOVAs showed significant differences $\left(\mathrm{Fs}_{(2 ; 71)}>3.05 ; \mathrm{ps}<0.05\right)$. These differences were explained by reduced length $(p<0.05)$, spine counts $(p<0.001)$ and spine density $(p<0.001)$ due to age ("old" versus "young"), and 
reversal of reduced spine counts $(p<0.01)$ and spine density $(p<0.05)$ after chronic treatment with GL-II73.

Dendritic length, spine count and spine density in the CA1 of the hippocampus were also quantified in the apical segment of young, old and old+GL-II-73 mice (Fig.4A-C). Repeated measure ANOVAs showed significant differences between groups in all three parameters $\left(\mathrm{Fs}_{(2 ; 143)}>6.9 ; \mathrm{ps}<0.05\right)$. Post hoc analyses identified these differences to be due to a significant decrease of dendritic length $(p<0.01)$, spine counts $(p<0.001)$ and spine density $(p<0.001)$ with aging ("old" versus "young"). Additionally, reduced dendritic length and spine count in old mice was reversed with chronic GL-II-73 treatment (ps<0.05).

Since the quantification of the dendritic length, spine count and spine density were performed in the PFC and CA1 of the same animals, we performed correlation analyses. Linear regression showed positive correlation between the apical dendritic lengths (Fig4.D) in the PFC and the CA1 ( $r=0.597 ; p=0.04)$ and between apical spine count (Fig4.E) in the PFC and CA1 ( $r=0.576 ; p=0.04)$. A trend was observed for the apical spine density (Fig.4F; $r=0.5383 ; p=0.07$ ).

\section{Cessation of treatment alters the pro-cognitive efficacy, but does not reduce the cellular effects.}

A separate cohort of mice was tested in the $Y$ maze after 30 days of treatment with GL-II-73, or after 30 days of treatment and a subsequent washout period of 1 week ("washout" group; Fig5.A). ANCOVA performed on the alternation rate showed significant differences between groups $\left(F_{(3 ; 17)}=9.48 ; p=0.007\right)$, explained by significant decrease of alternation with aging ("old" versus "young": $p<0.01$ ), reversed by chronic treatment ("old+GL-II-73" versus "old":p<0.01). However, mice in the "washout" group had decreased alternation rate compared to "young" and "old+GL-II-73" (ps<0.01; Fig.5B).

After completion of the behavioral testing, mice were euthanized and brains collected for Golgi staining (supplementary Figure 4). ANOVA performed on total dendritic length, spine counts and spine density in the PFC were performed $\left(\mathrm{Fs}_{(3,188)}>3.5 ; \mathrm{ps}<0.05\right.$; Supplementary Figure 5). These differences were explained by a decrease of dendritic length in old mice, compared to young mice $(p<0.05)$. Regarding the total spine counts, old mice showed decreased spine counts compared to young $(p<0.001)$, that was reversed by chronic treatment with GL-II-73 ("old+GL-II-73" versus "old"; $p<0.001$ ) even after a 1-week washout ("old+washout" versus "old"; $p<0.001$ ). The significant differences in the total spine density were explained by reduced spine density in old mice compared to young $(p<0.001)$, partially reversed by chronic treatment, even with a 1-week washout ("old" versus "old+GL-II-73", "old" versus "old+washout", "young" versus "old+GL-II-73" and "young" versus "old+washout": ps<0.05). In the apical segment, 
ANOVA on the total dendritic length did not reach significance ( $p=0.1 ;$ Fig.5C). ANOVAs performed on the apical spine counts and spine density reached significance $\left(F_{(3,188)}>9.6 ; p<0.001\right)$. The significant difference in the apical spine count (Fig.5D) was explained by reduced spine count during aging ("old" versus "young": p<0.001), reversed by chronic treatment with GL-II-73 (“Old+GL-II-73" versus "old":p<0.05), even with a 1-week washout ("old+washout" versus "old": p<0.001). Finally, the significant difference in apical spine density (Fig.5E) in the PFC was explained by a significant decrease with age ("old" versus “young": $p<0.001$ ), partially reversed by chronic treatment with GL-II-73 ("old+GL-II-73" versus "old" and "young"; ps<0.01), and fully reversed by chronic treatment with a 1-week washout ("old+washout" versus "old":p<0.001). In the basal segment, ANOVAs performed on the spine counts and the spine density showed significant differences $\left(F_{(3,188)}>9.1 ; p s<0.001\right)$ but not on the dendritic length $\left(F_{(3,188)}>2.3 ; p=0.07\right)$ (supplementary Figure 5D-F). Spine count and density in the basal segment were decreased with aging ("old" versus "young": ps<0.001), and reversed by chronic treatment ("old+GL-II-73" versus "old": ps<0.05), even with a 1-week washout ("old+washout" versus "old": ps<0.05).

Similar analyses were performed on the dendritic length, spine count and spine density in the CA1 of the same animals (supplementary Figure 6). The data obtained in the CA1 confirmed what was shown in the PFC. There were no significant differences in total, basal or apical dendritic length (data not shown). A significant difference was found in total spine count $\left(F_{(3,188)}=8.95 ; p<0.001\right)$, explained by a decrease in spine count with age ("old" versus "young": $p<0.001$ ), that was significantly reversed only in the washout group ("old+washout" versus "old": p<0.001; Supplementary Figure 7A). The same effects were observed when looking specifically at the basal and apical segment (Supplementary Figure 7B-C). Total spine density was also showing significant differences (ANOVA $F_{(3,188)}=25.65, p<0.001$; supplementary Figure 7D), explained by decreased density with aging ("old" versus "young": $p<0.001$ ), partially reversed by chronic treatment ("Old+GL-II-73" versus "old" and "young": ps<0.01), even with a 1-week washout ("old+washout" versus "old" and "young": ps<0.05). The decrease in spine density with age was confirmed in the basal and apical segments (ANOVAs $\mathrm{Fs}_{(3,188)}>10.5$; $\mathrm{ps}<0.01$ ), as well as the reversal with chronic treatment with GL-II-73, even with a 1-week washout (Supplementary Figure 7E-F). 


\section{Discussion}

This study was based on the observation that normal aging induces neuronal loss contributing to cognitive decline. Here, we first confirmed that normal aging in mice induces cognitive deficits, with old mice exhibiting impaired working memory in the alternation task, consistent with previous finding (59, $63,64)$. Many compounds (65), drugs (66), natural extracts (64) or physical exercises (67) demonstrated potential at reversing cognitive decline in animal models, but with little-to-no success in human populations $(68,69)$. This lack of efficacy can partially be explained by the focus of such approaches aiming at reversing the symptoms more than the underlying pathology. Indeed, it is unclear at the moment if treatment avenues that show pro-cognitive efficacy actually alleviate the underlying pathology, such as neuronal dysfunction or neuronal shrinkage. Companion tools, like radio-ligands for PET imaging can be developed to demonstrate such efficacy, but priority is still given at alleviating the symptoms.

In the context of aging, the "morphomolecular" senescence has a broad impact on different systems, including the GABAergic system. Reduced GABAergic functions are a hallmark of aging, and previous studies from our group demonstrated that targeting $\alpha_{5}$-GABAA receptors to bypass such deficits could reverse age-related cognitive decline (59). In the present study, we investigated the potential combined efficacy of GL-II-73 on symptoms and underlying pathology, i.e. neuronal shrinkage. We demonstrated that chronic treatment with GL-II-73 not only reverses cognitive decline, but also reverses dendritic shrinkage and spine atrophy in the PFC and the CA1. Indeed, chronic treatment with GL-II-73 increased dendritic length, spine count and spine density in the both brain regions, in old mice. To our knowledge, it is the first time that a drug acting on the GABAergic system demonstrates neurotrophic effects, while commonly used benzodiazepines seem to decrease spine density in cortical pyramidal neurons (70). Other drugs have shown neurotrophic effects (71), such as ketamine for the treatment of depressive episodes (72). Recent studies have shown that the antidepressant action of ketamine is mediated by its activity on NMDA receptor of GABA neurons $(73,74)$. Further studies will be needed to identify what could be the mechanism of action of GL-II-73 allowing this neurotrophic effect, and if it has shared pathways with ketamine.

Interestingly, the neurotrophic effect of GL-II-73 was more pronounced in the apical segment of the pyramidal neuron dendrites compared to the basal segment. It is known that the $\alpha_{5}$-GABA-A receptors are located in the apical segment of the pyramidal neurons (52), so these results suggest that the $\alpha_{5-}$ GABA-A receptors directly mediate this neurotrophic effect. However, a significant increase of spine counts and spine density in basal segment of pyramidal neurons of the CA1 from the treatment group was 
also observed. This effect can either suggest the potential presence of the $\alpha_{5}$-GABA-A receptors in the basal segment of pyramidal neurons of the CA1, or a generalized effect happening downstream of the apical effect. Such hypotheses would need to be validated but is consistent with previous finding showing that the $\alpha_{5}$-GABA-A receptors are involved in the dendritic outgrowth and spine maturation of pyramidal neurons (56).

When the drug is no longer given to the animals, the neurotrophic effect remains but the pro-cognitive effect diminishes. One could argue that the drug needs to be on board to improve cognitive performances continuously, even in the event of a strong neurotrophic effect. This would suggest that the neurotrophic effect alone is not sufficient to recover normal cognitive processes, and suggests that the "rejuvenated" neurons are not as functional as neurons of younger animals. Here, we did not investigate if the "rejuvenated" neurons were similarly functional compared to neurons from younger animals, or if their functions were more similar to neurons from old animals. Using slice electrophysiology could answer thia question and investigate if these neurons were truly rejuvenated or if the neurotrophic effect was limited to morphological features. In addition, the present study only tested 1 treatment duration (4 weeks) and 1 washout period (1 week). Investigating if longer treatment with GL-II-73 improves the stability of the cognitive functions when the treatment is spotted could be a solution to improve the functions of the rejuvenated neurons.

Despite promising results in mice suggesting a relief of the cognitive symptoms and a rejuvenation of neurons in brain regions involved in cognitive processes, it would be naïve to think that a single drug could reverse all the changes induced by normal aging. However, GL-II-73 is the first drug targeting an inhibitory system that shows neurotrophic, associated with symptom relief. With its potential anxiolytic and antidepressant effects (59), GL-II-73 could become a game changer for patients suffering from cognitive decline due to GABAergic downregulation. In the context of aging, and early stages of Alzheimer's disease, GL-II-73 could possibly be paired with Aducanumab(35), a potent monoclonal antibody directed against $\beta$-amyloid oligomers, to further slowdown the progression of the disease and strengthen neuronal "health" and cognitive functions. Further testing in other cognitive domains, and other models (Alzheimer's disease, neurodegenerative disease etc.) will demonstrate the validity of this new drug for future therapeutic uses. 


\section{Figure Legends}

Figure 1. Effect of $\alpha_{5}$-PAM on dendrite morphology and spine numbers in primary cortical neurons in vitro.

Cortical neurons were cultured from embryos of mice expressing the fluorescent protein GFP in pyramidal neurons (CamKII positive neurons). Neurons were cultured for 25 days and then incubated with Vehicle (0.01\% DMSO in media) or GL-II-73 (1 $1 \mu \mathrm{M})$. (A) After $24 \mathrm{hrs}$ of incubation with GL-II-73, or vehicle, isolated neurons were imaged in order to analyze the morphology and the spine number. (B) Using the Sholl Analysis package of the software ImageJ, the number of intersections every $10 \mu \mathrm{m}$ from the soma was analyzed. A significant increase in the number of intersections was identified in the neurons incubated with GL-II-73 between 30 and $50 \mu \mathrm{m}$ of distance from the soma. (C) Spine counts were also increased after incubation of GL-II-73. ${ }^{*} p<0.05 .{ }^{* * *} p<0.001$.

\section{Figure 2. Chronic treatment with GL-II-73 reverses age-related deficit in Working memory}

C57BL/6 male mice were used: young (2-month old) and old (22-month old). (A) Old mice received GL-II73 in the drinking water $(\mathrm{N}=8)$, or water $(\mathrm{N}=14)$ while young mice only received water $(\mathrm{N}=11)$. After 30 days of treatment, mice were tested in the open-field to assess locomotor activity. (B) No significant differences in the total distance travelled were observed between young, old and old+GL-II-73 mice. (C) Mice were then trained in the alternation task in the Y Maze. ANOVA revealed a significant difference in alternation between groups, explained by a decreased alternation in old mice, compared to young, that is reversed by chronic treatment with GL-II-73. $+++p<0.001$ compared to "young"; ** $<<0.01$ compared to "old". Dash line represents chance level.

Figure 3. Chronic treatment with GL-II-73 reverses cellular morphology changes related to aging in the PFC

After completion of the behavioral screening, mice were euthanized and brains were stained with GolgiCox solution. (A) Pyramidal neurons $(\mathrm{N}=6)$ from 4 mice per group were analyzed for dendritic length, spine counts and spine density. Basal (B) and apical (C) dendritic lengths were measured. No statistical differences were observed in the basal segment, but ANOVA in the apical segment revealed significant differences between groups. This difference was explained by a decrease in dendritic length in old mice compared to young mice that was reversed by chronic treatment with GL-II-73. (D-E) In the same brain region, basal and apical spine counts were assessed. In the basal segment, a significant decrease was observed in old mice. In the apical segment, a similar decrease was observed with age that was reversed by chronic treatment with GL-II-73. Similarly, basal (F) and apical (G) spine density were measured. With age, a significant decrease in spine density was observed in the basal segment, and in the apical segment. However, chronic treatment with GL-II-73 only reversed this decreased in the apical segment. ${ }^{*} \mathrm{p}<0.05$, ${ }^{* *} p<0.01, * * * p<0.001$ compared to "old". 
Figure 4. Chronic treatment with GL-II-73 reverses cellular morphology changes related to aging in the CA1, in a similar manner than the PFC

The same brains were analyzed for dendritic length, spine count and spine density in the CA1 of the hippocampus. (A) Dendritic length in the apical segment was significantly decreased by aging. Chronic treatment with GL-II-73 significantly reversed the reduced dendritic length in old mice. (B) Spine counts in the apical segment were also reduced with age. Chronic treatment with GL-II-73 reversed the reduced spine counts in old mice. (C) Spine density in the apical segment of pyramidal neurons in the CA1 was also significantly decreased in old mice. Chronic treatment with GL-II-73 did not significantly reversed the spine density reduction induced by aging. (D) Linear regression between dendritic length in the CA1 and the PFC showed positive correlation ( $p=0.04)$. (E) Similarly, spine count in the PFC an the CA1 were also correlated, suggesting a link between the effects observed in the PFC and the CA1. (F) Linear regression between the spine density in the PFC and the CA1 did not reach significance $(p=0.07) .{ }^{*} p<0.05,{ }^{* *} p<0.01, * * * p<0.001$ compared to "old".

Figure 5. Cessation of chronic treatment with GL-II-73 limits the precognitive efficacy but does not alter the effect on dendritic morphology

C57BL/6 male mice were used: young (2-month old) and old (22-month old). (A) Old mice received GL-II73 in the drinking water $(\mathrm{N}=6)$, or water $(\mathrm{N}=6)$, or $\mathrm{GL}-1 \mathrm{l}-73$ for 30 days followed by 7 days of washout $(\mathrm{N}=6)$ while young mice only received water $(\mathrm{N}=8)$. (B) After completion of the treatment schedule, mice were trained in the alternation task in the $Y$ Maze. ANOVA revealed a significant difference in alternation between groups, explained by a decreased alternation in old mice, compared to young, that is reversed by chronic treatment with GL-II-73. However, the 7-day washout limited the precognitive effect. After completion of the behavioral testing, mice were euthanized, brains were collected and stained for morphology analyzes, and apical morphology features were measured. (C) ANOVA performed on the apical dendritic length did not reach significance $(p>0.05)$. (D) ANOVA performed on the apical spine count reached significance $(p<0.05)$, and could be explained by a decrease of spine count with age, that is reversed with chronic treatment with GL-II-73, even after a washout period. (E) Similar findings were obtained with apical spine density measurement, where age decreased spine density, but chronic treatment with GL-II-73 reversed this deficit, even after a 7-day washout.

$++p<0.01,+++p<0.001$ compared to "young"; *p<0.05, **p<0.01, ***p<0.001 compared to "old"; $\wedge \wedge p<0.01$ compared to "old+GL-II-73". Dash line represents chance level. 


\section{References}

1. Nations U. World Population Ageing Report 2015.

2. Nations U. World Population Prospects: the 2019 Revision. 2019.

3. Nations U. Global Issues: Ageing. 2019.

4. Harada CN, Natelson Love MC, Triebel KL. Normal cognitive aging. Clin Geriatr Med. 2013;29(4):737-52.

5. Moscoso Del Prado Martin F. Vocabulary, Grammar, Sex, and Aging. Cogn Sci. 2017;41(4):950-75.

6. Teubner-Rhodes S, Vaden KI, Jr., Cute SL, Yeatman JD, Dougherty RF, Eckert MA. Aging-Resilient Associations between the Arcuate Fasciculus and Vocabulary Knowledge: Microstructure or Morphology? J Neurosci. 2016;36(27):7210-22.

7. Zahr NM, Rohlfing T, Pfefferbaum A, Sullivan EV. Problem solving, working memory, and motor correlates of association and commissural fiber bundles in normal aging: a quantitative fiber tracking study. Neuroimage. 2009;44(3):1050-62.

8. Nyberg L, Lovden M, Riklund $K$, Lindenberger $U$, Backman L. Memory aging and brain maintenance. Trends Cogn Sci. 2012;16(5):292-305.

9. Salthouse TA. Memory Aging From 18 to 80. Alzheimer Disease \& Associated Disorders. 2003;17(3):162-7.

10. Salthouse TA. Aging and measures of processing speed. Biological Psychology. 2000;54(1):35-54.

11. Shanmugaratnam S, Kass SJ, Arruda JE. Age differences in cognitive and psychomotor abilities and simulated driving. Accid Anal Prev. 2010;42(3):802-8.

12. Souchay C, Isingrini M, Espagnet L. Aging, episodic memory feeling-of-knowing, and frontal functioning. Neuropsychology. 2000;14(2):299-309.

13. Salthouse TA. The aging of working memory. Neuropsychology. 1994;8(4):535-43.

14. Hof PR, Morrison JH. The aging brain: morphomolecular senescence of cortical circuits. Trends Neurosci. 2004;27(10):607-13.

15. Terribilli D, Schaufelberger MS, Duran FLS, Zanetti MV, Curiati PK, Menezes PR, et al. Age-related gray matter volume changes in the brain during non-elderly adulthood. Neurobiology of aging. 2011;32(2):354-68.

16. Apostolova LG, Green AE, Babakchanian S, Hwang KS, Chou Y-Y, Toga AW, et al. Hippocampal atrophy and ventricular enlargement in normal aging, mild cognitive impairment ( $\mathrm{MCl})$, and Alzheimer Disease. Alzheimer Dis Assoc Disord. 2012;26(1):17-27.

17. Terry RD, DeTeresa R, Hansen LA. Neocortical cell counts in normal human adult aging. Ann Neurol. 1987;21(6):530-9.

18. Cykowski MD, Powell SZ, Schulz PE, Takei H, Rivera AL, Jackson RE, et al. Hippocampal Sclerosis in Older Patients: Practical Examples and Guidance With a Focus on Cerebral Age-Related TDP-43 With Sclerosis. Archives of Pathology \& Laboratory Medicine. 2017;141(8):1113-26.

19. Luebke JI, Medalla M, Amatrudo JM, Weaver CM, Crimins JL, Hunt B, et al. Age-Related Changes to Layer 3 Pyramidal Cells in the Rhesus Monkey Visual Cortex. Cerebral Cortex. 2013;25(6):1454-68.

20. De Brabander J, Kramers R, Uylings $\mathrm{H}$. Layer - specific dendritic regression of pyramidal cells with ageing in the human prefrontal cortex. European Journal of Neuroscience. 1998.

21. Shukla R, Prevot TD, French L, Isserlin R, Rocco BR, Banasr M, et al. The Relative Contributions of Cell-Dependent Cortical Microcircuit Aging to Cognition and Anxiety. Biol Psychiatry. 2019;85(3):257-67.

22. Jacobs B, Driscoll L, Schall M. Life-span dendritic and spine changes in areas 10 and 18 of human cortex: A quantitative golgi study. Journal of Comparative Neurology. 1997;386(4):661-80.

23. Wallace $M$, Frankfurt $M$, Arellanos $A$, Inagaki $T$, Luine $V$. Impaired recognition memory and decreased prefrontal cortex spine density in aged female rats. Ann N Y Acad Sci. 2007;1097:54-7. 
24. Dickstein DL, Weaver CM, Luebke JI, Hof PR. Dendritic spine changes associated with normal aging. Neuroscience. 2013;251:21-32.

25. Ownby RL. Neuroinflammation and cognitive aging. Curr Psychiatry Rep. 2010;12(1):39-45.

26. Nishimura I, Uetsuki T, Dani SU, Ohsawa Y, Saito I, Okamura H, et al. Degeneration in vivo of rat hippocampal neurons by wild-type Alzheimer amyloid precursor protein overexpressed by adenovirusmediated gene transfer. Journal of Neuroscience. 1998;18(7):2387-98.

27. Ten Kate M, Barkhof F, Visser PJ, Teunissen CE, Scheltens P, Van Der Flier WM, et al. Amyloidindependent atrophy patterns predict time to progression to dementia in mild cognitive impairment. Alzheimer's research \& therapy. 2017;9(1):73.

28. Rodrigue KM, Kennedy KM, Devous MD, Sr., Rieck JR, Hebrank AC, Diaz-Arrastia R, et al. betaAmyloid burden in healthy aging: regional distribution and cognitive consequences. Neurology. 2012;78(6):387-95.

29. Rodrigue KM, Kennedy KM, Park DC. Beta-amyloid deposition and the aging brain. Neuropsychol Rev. 2009;19(4):436-50.

30. Deng X, Li M, Ai W, He L, Lu D, Patrylo PR, et al. Lipolysaccharide-induced neuroinflammation is associated with Alzheimer-like amyloidogenic axonal pathology and dendritic degeneration in rats. Advances in Alzheimer's disease. 2014;3(2):78.

31. Fuhrmann M, Mitteregger G, Kretzschmar H, Herms J. Dendritic pathology in prion disease starts at the synaptic spine. Journal of Neuroscience. 2007;27(23):6224-33.

32. Heneka MT, Carson MJ, Khoury JE, Landreth GE, Brosseron F, Feinstein DL, et al. Neuroinflammation in Alzheimer's disease. The Lancet Neurology. 2015;14(4):388-405.

33. Jack CR, Jr., Lowe VJ, Senjem ML, Weigand SD, Kemp BJ, Shiung MM, et al. 11C PiB and structural MRI provide complementary information in imaging of Alzheimer's disease and amnestic mild cognitive impairment. Brain. 2008;131(Pt 3):665-80.

34. Pike KE, Savage G, Villemagne VL, Ng S, Moss SA, Maruff $P$, et al. Beta-amyloid imaging and memory in non-demented individuals: evidence for preclinical Alzheimer's disease. Brain. 2007;130(Pt 11):2837-44.

35. Panza F, Lozupone M, Logroscino G, Imbimbo BP. A critical appraisal of amyloid- $\beta$-targeting therapies for Alzheimer disease. Nature Reviews Neurology. 2019;15(2):73-88.

36. Doig AJ, Del Castillo-Frias MP, Berthoumieu O, Tarus B, Nasica-Labouze J, Sterpone F, et al. Why Is Research on Amyloid- $\beta$ Failing to Give New Drugs for Alzheimer's Disease? ACS chemical neuroscience. 2017;8(7):1435-7.

37. Wong TP, Marchese G, Casu MA, Ribeiro-da-Silva A, Cuello AC, De Koninck Y. Imbalance towards inhibition as a substrate of aging-associated cognitive impairment. Neurosci Lett. 2006;397(1-2):64-8.

38. Legon W, Punzell S, Dowlati E, Adams SE, Stiles AB, Moran RJ. Altered Prefrontal Excitation/Inhibition Balance and Prefrontal Output: Markers of Aging in Human Memory Networks. Cereb Cortex. 2016;26(11):4315-26.

39. Hua T, Kao C, Sun Q, Li X, Zhou Y. Decreased proportion of GABA neurons accompanies age-related degradation of neuronal function in cat striate cortex. Brain Research Bulletin. 2008;75(1):119-25.

40. Sibille E. Molecular aging of the brain, neuroplasticity, and vulnerability to depression and other brain-related disorders. Dialogues in clinical neuroscience. 2013;15(1):53-65.

41. Stanley EM, Fadel JR, Mott DD. Interneuron loss reduces dendritic inhibition and GABA release in hippocampus of aged rats. Neurobiology of Aging. 2012;33(2):431.e1-.e13.

42. Cuypers K, Maes C, Swinnen SP. Aging and GABA. Aging. 2018;10(6):1186-7.

43. Bormann J. The ' $A B C$ ' of GABA receptors. Trends in Pharmacological Sciences. 2000;21(1):16-9.

44. Möhler H. GABA(A) receptor diversity and pharmacology. Cell Tissue Res. 2006;326(2):505-16.

45. Rozycka A, Liguz-Lecznar M. The space where aging acts: focus on the GABAergic synapse. Aging Cell. 2017;16(4):634-43. 
46. Caspary DM, Hughes LF, Ling LL. Age-related GABAA receptor changes in rat auditory cortex. Neurobiology of aging. 2013;34(5):1486-96.

47. Yu Z-Y, Wang W, Fritschy J-M, Witte OW, Redecker C. Changes in neocortical and hippocampal GABAA receptor subunit distribution during brain maturation and aging. Brain research. 2006;1099(1):7381.

48. Ruano D, Araujo F, Revilla E, Vela J, Bergis O, Vitorica J. GABAA and $\alpha$-amino-3-hydroxy-5methylsoxazole-4-propionate receptors are differentially affected by aging in the rat hippocampus. Journal of Biological Chemistry. 2000;275(26):19585-93.

49. Rissman RA, De Blas AL, Armstrong DM. GABAA receptors in aging and Alzheimer's disease. Journal of neurochemistry. 2007;103(4):1285-92.

50. Luscher B, Fuchs T, Kilpatrick Casey L. GABAA Receptor Trafficking-Mediated Plasticity of Inhibitory Synapses. Neuron. 2011;70(3):385-409.

51. Rissman RA, Mobley WC. Implications for treatment: GABAA receptors in aging, Down syndrome and Alzheimer's disease. Journal of neurochemistry. 2011;117(4):613-22.

52. Hörtnagl H, Tasan RO, Wieselthaler A, Kirchmair E, Sieghart W, Sperk G. Patterns of mRNA and protein expression for 12 GABAA receptor subunits in the mouse brain. Neuroscience. 2013;236:345-72.

53. Howell O, Atack J, Dewar D, McKernan R, Sur C. Density and pharmacology of $\alpha 5$ subunitcontaining GABAA receptors are preserved in hippocampus of Alzheimer's disease patients. Neuroscience. 2000;98(4):669-75.

54. Rissman R, Mishizen-Eberz A, Carter T, Wolfe B, De Blas A, Miralles $C$, et al. Biochemical analysis of GABAA receptor subunits $\alpha 1, \alpha 5, \beta 1, \beta 2$ in the hippocampus of patients with Alzheimer's disease neuropathology. Neuroscience. 2003;120(3):695-704.

55. Rissman RA, Bennett DA, Armstrong DM. Subregional analysis of GABAA receptor subunit mRNAs in the hippocampus of older persons with and without cognitive impairment. Journal of chemical neuroanatomy. 2004;28(1-2):17-25.

56. Brady ML, Jacob TC. Synaptic localization of $\alpha 5$ GABA (A) receptors via gephyrin interaction regulates dendritic outgrowth and spine maturation. Developmental neurobiology. 2015;75(11):1241-51. 57. Sigel $E$, Ernst $M$. The Benzodiazepine Binding Sites of $\operatorname{GABA}(A)$ Receptors. Trends in pharmacological sciences. 2018;39(7):659-71.

58. Markota M, Rummans TA, Bostwick JM, Lapid MI. Benzodiazepine Use in Older Adults: Dangers, Management, and Alternative Therapies. Mayo Clinic Proceedings. 2016;91(11):1632-9.

59. Prevot TD, Li G, Vidojevic A, Misquitta KA, Fee C, Santrac A, et al. Novel Benzodiazepine-Like Ligands with Various Anxiolytic, Antidepressant, or Pro-Cognitive Profiles. Mol Neuropsychiatry. 2019;5(2):84-97.

60. Koh MT, Rosenzweig-Lipson S, Gallagher M. Selective GABA(A) alpha5 positive allosteric modulators improve cognitive function in aged rats with memory impairment. Neuropharmacology. 2013;64:145-52.

61. Tomoda $T$, Sumitomo A, Shukla R, Hirota-Tsuyada $\mathrm{Y}$, Miyachi $\mathrm{H}, \mathrm{Oh} \mathrm{H}$, et al. BDNF controls cognitive processes related to neuropsychiatric manifestations via autophagic regulation of p62 and GABA<sub $>A</$ sub $>$ receptor trafficking. bioRxiv. 2019:334466.

62. Wu C-C, Chawla F, Games D, Rydel RE, Freedman S, Schenk D, et al. Selective vulnerability of dentate granule cells prior to amyloid deposition in PDAPP mice: Digital morphometric analyses. Proceedings of the National Academy of Sciences of the United States of America. 2004;101(18):7141-6.

63. Magnusson KR, Scruggs B, Aniya J, Wright KC, Ontl T, Xing Y, et al. Age-related deficits in mice performing working memory tasks in a water maze. Behavioral Neuroscience. 2003;117(3):485-95.

64. Beracochea D, Krazem A, Henkouss N, Haccard G, Roller M, Fromentin E. Intake of Wild Blueberry Powder Improves Episodic-Like and Working Memory during Normal Aging in Mice. Planta Med. 2016;82(13):1163-8. 
65. Vandesquille M, Krazem A, Louis C, Lestage P, Béracochéa D. S 18986 reverses spatial working memory impairments in aged mice: comparison with memantine. Psychopharmacology. 2011;215(4):709-

20.

66. Van Dam D, Abramowski D, Staufenbiel M, De Deyn PP. Symptomatic effect of donepezil, rivastigmine, galantamine and memantine on cognitive deficits in the APP23 model. Psychopharmacology. 2005;180(1):177-90.

67. Ma C-L, Ma X-T, Wang J-J, Liu H, Chen Y-F, Yang Y. Physical exercise induces hippocampal neurogenesis and prevents cognitive decline. Behavioural Brain Research. 2017;317:332-9.

68. Garner JP. The significance of meaning: why do over $90 \%$ of behavioral neuroscience results fail to translate to humans, and what can we do to fix it? ILAR J. 2014;55(3):438-56.

69. Al Dahhan NZ, De Felice FG, Munoz DP. Potentials and Pitfalls of Cross-Translational Models of Cognitive Impairment. Frontiers in Behavioral Neuroscience. 2019;13(48).

70. Curto Y, Garcia-Mompo C, Bueno-Fernandez C, Nacher J. Chronic benzodiazepine treatment decreases spine density in cortical pyramidal neurons. Neuroscience Letters. 2016;613:41-6.

71. Castrén E. Neurotrophic effects of antidepressant drugs. Current Opinion in Pharmacology. 2004;4(1):58-64.

72. Duman $\mathrm{CH}$, Duman RS. Spine synapse remodeling in the pathophysiology and treatment of depression. Neuroscience Letters. 2015;601:20-9.

73. Gerhard DM, Pothula S, Liu R-J, Wu M, Li X-Y, Girgenti MJ, et al. GABA interneurons are the cellular trigger for ketamine's rapid antidepressant actions. The Journal of clinical investigation. 2020:130808.

74. Ghosal S, Duman CH, Liu R-J, Wu M, Terwilliger R, Girgenti MJ, et al. Ketamine rapidly reverses stress-induced impairments in GABAergic transmission in the prefrontal cortex in male rodents. Neurobiology of Disease. 2020;134:104669. 

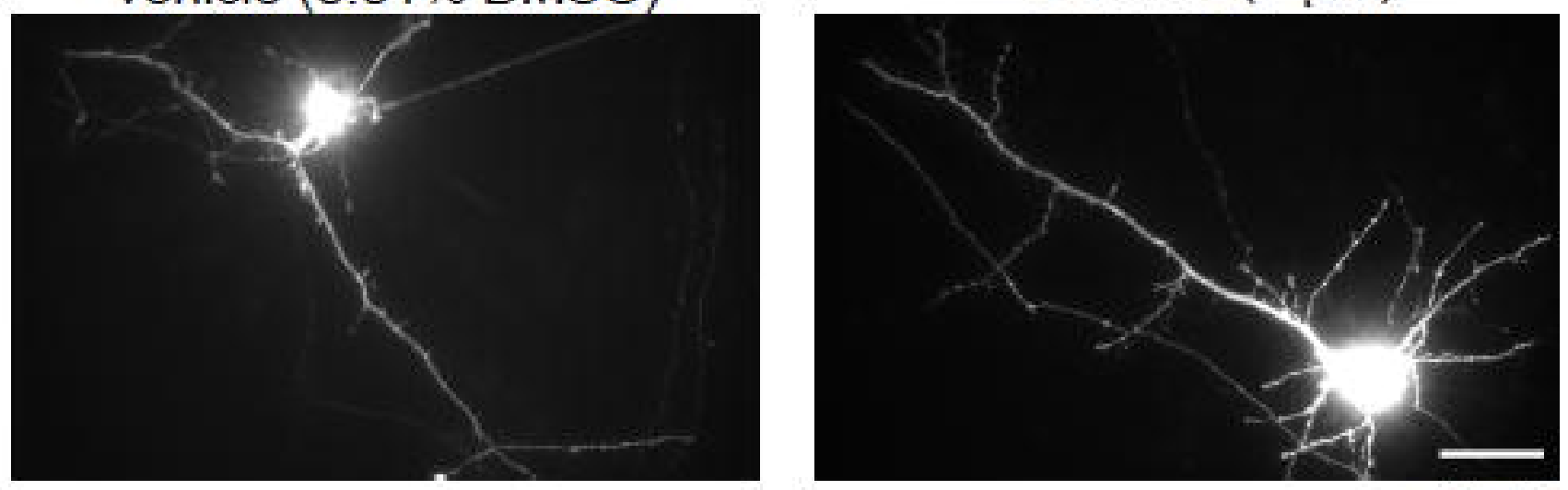

B

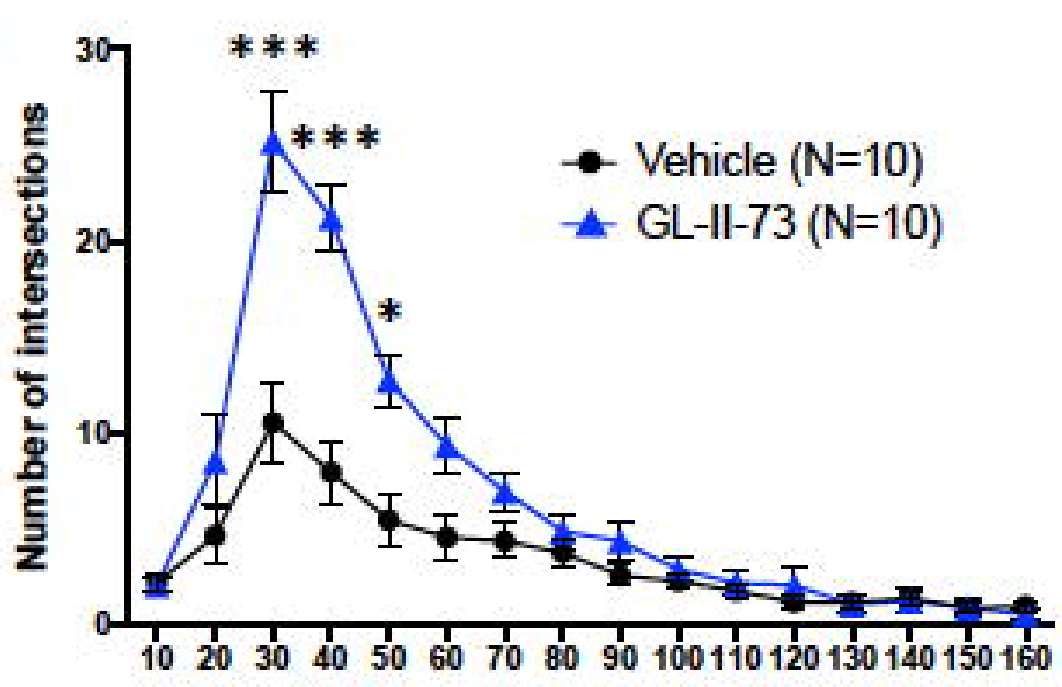

C

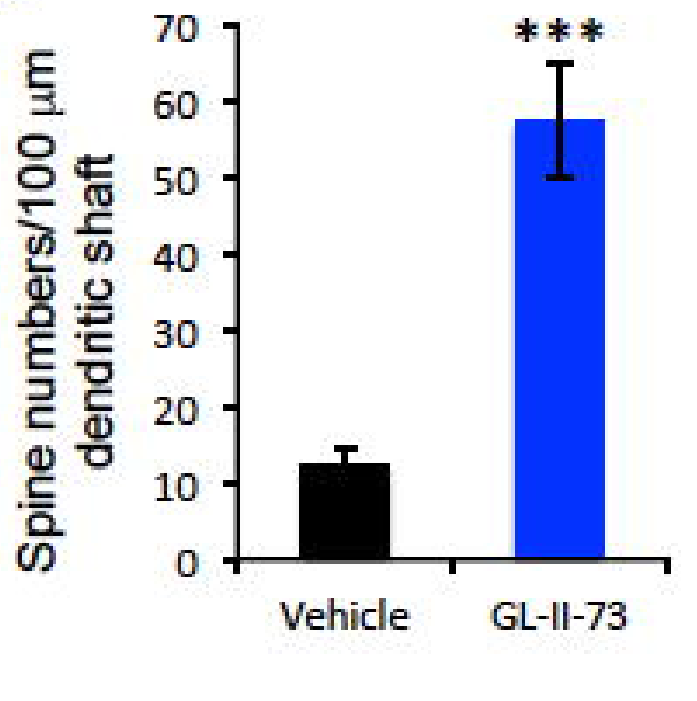
Distance from cell body $(\mu \mathrm{m})$ 


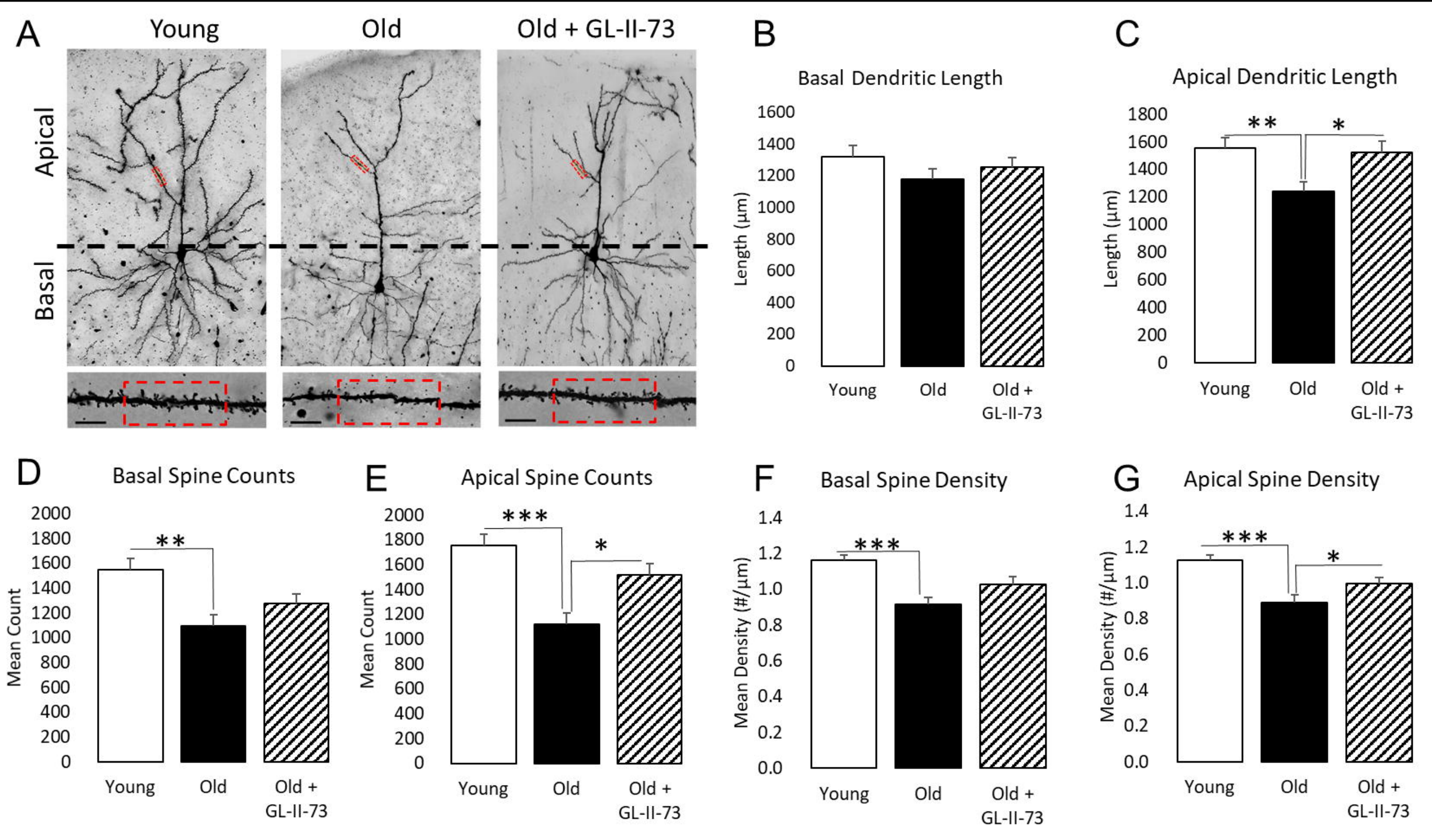




\section{A Apical Dendritic Length}

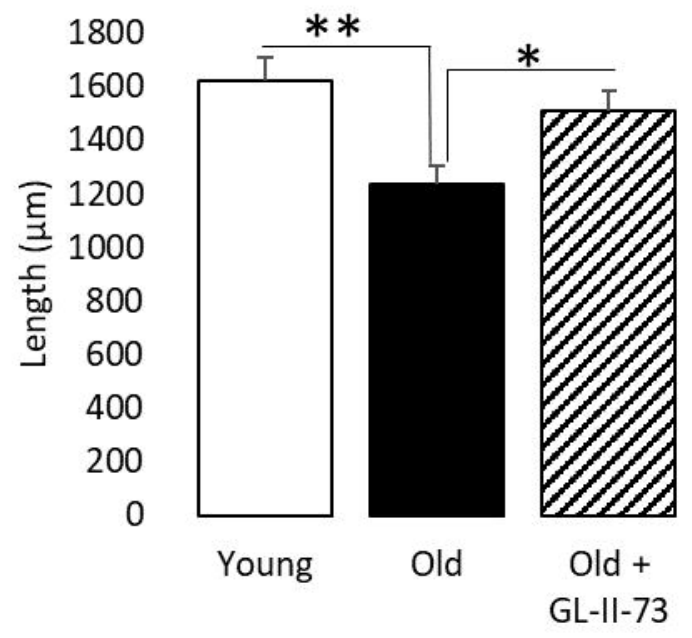

D

\section{Apical Dendritic Length}

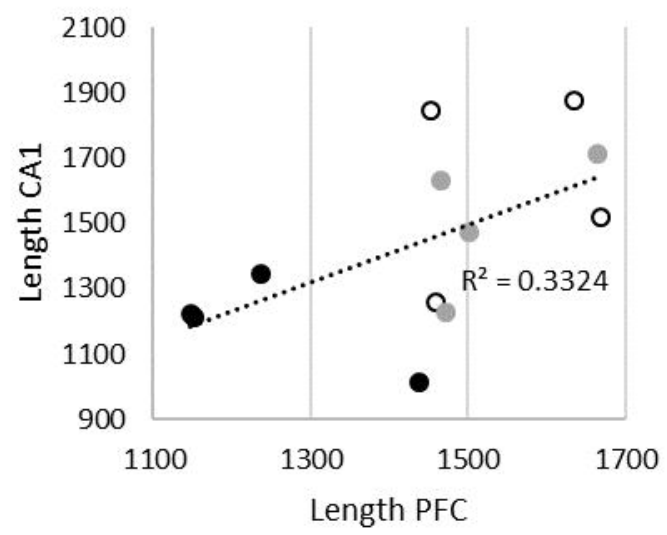

B Apical Spine Counts

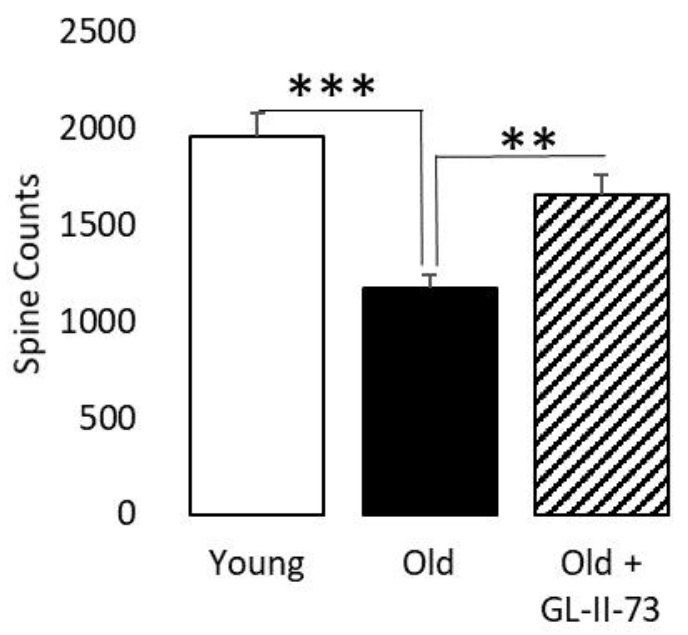

E

Apical Spine Counts

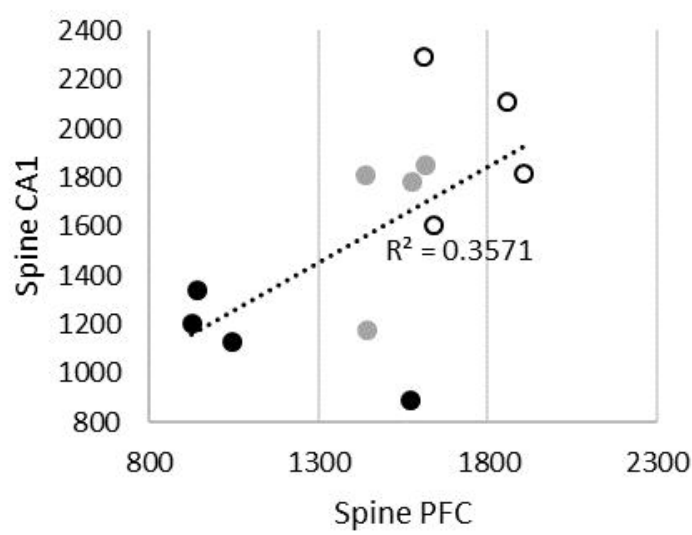

OYoung
C Apical Spine Density

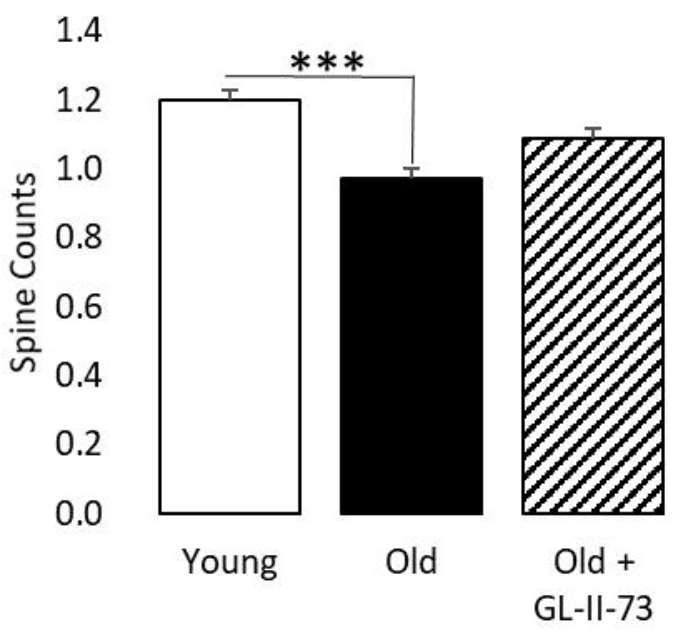

F

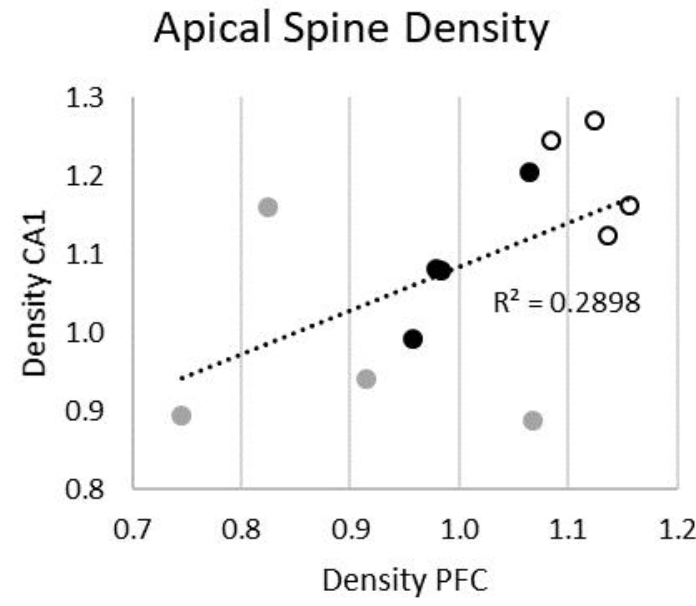

OYoung 


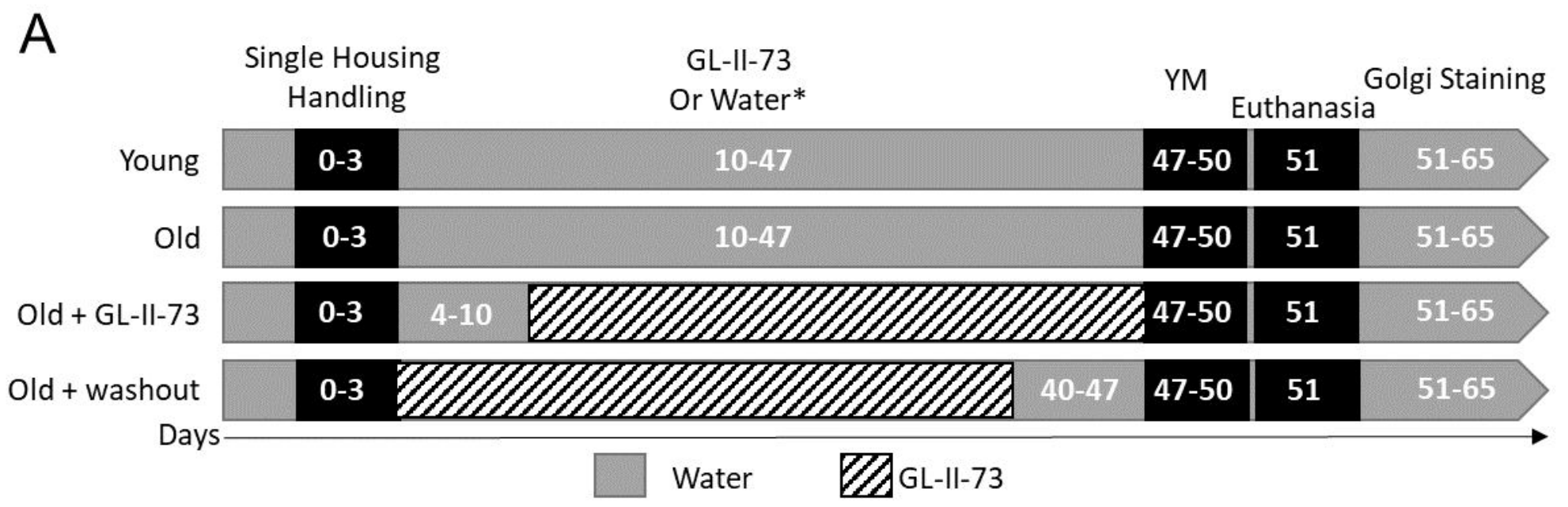

B

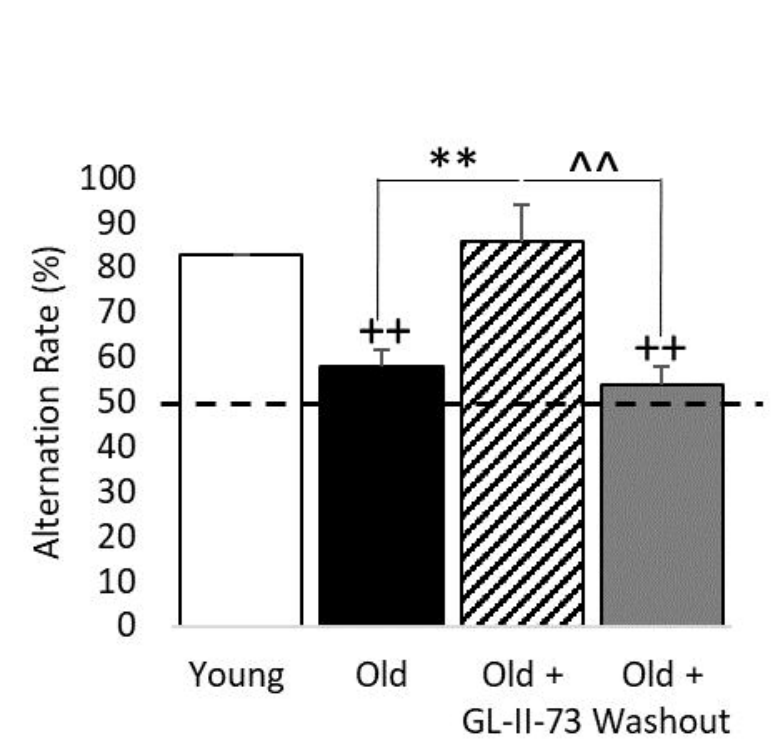

Apical Spine Count-PFC

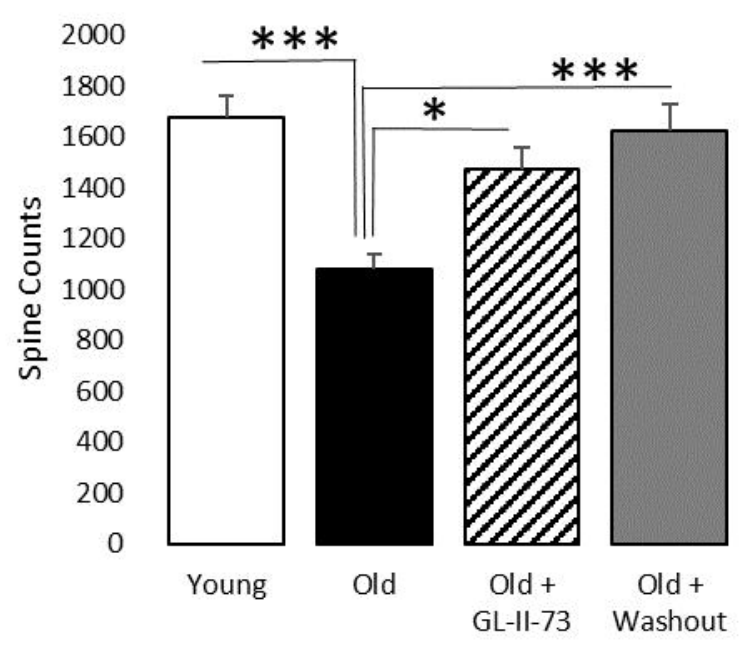

C

Apical Dendritic Length-PFC 1600

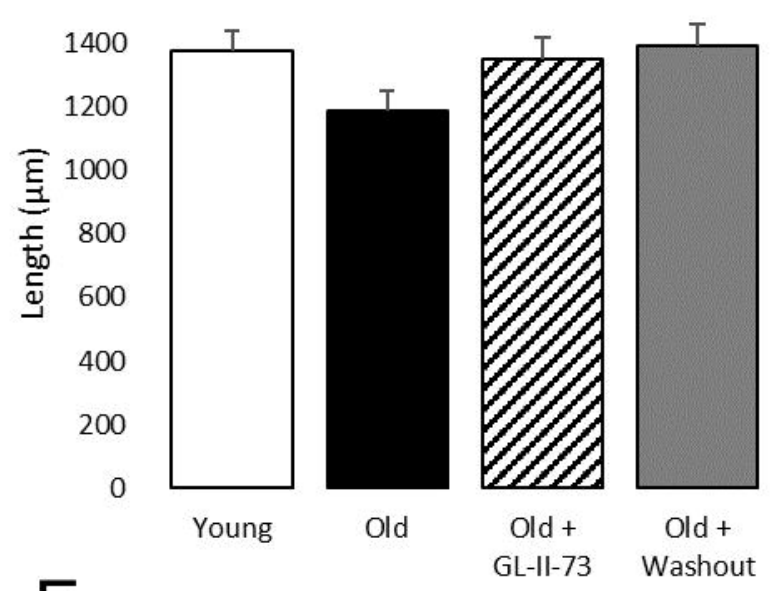

E

Apical Spine Density-PFC

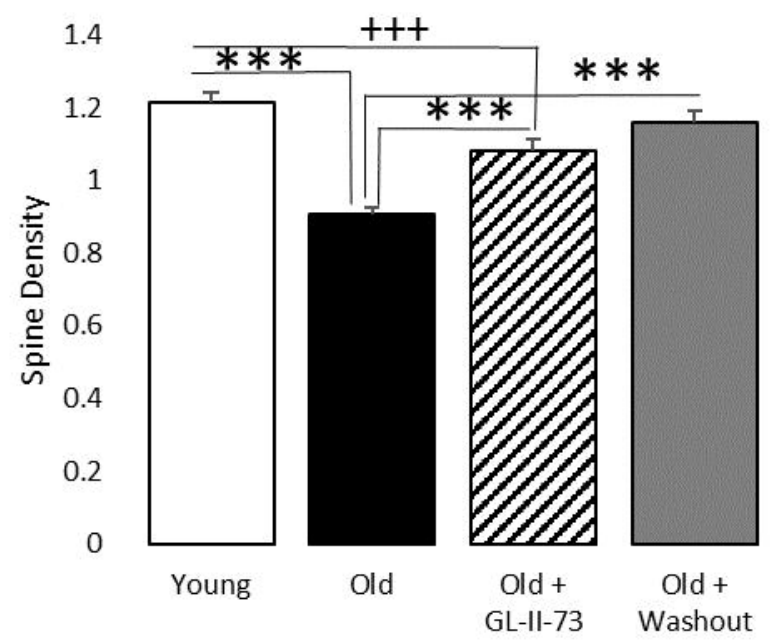

